\title{
Decrease in viral load at weeks 12 and 24 in patients with chronic hepatitis $B$ treated with lamivudine or adefovir predicts virological response at week 48
}

\author{
E. Llop, J. de la Revilla, F. Pons, B. Peñas, J. L. Martínez, L. Abreu and J. L. Calleja \\ Service of Gastroenterology and Hepatology. University Hospital Puerta de Hierro. Madrid, Spain
}

\begin{abstract}
Aim: the aim of our study was to evaluate the decrease in viral load (VL) that is able to predict antiviral treatment response at one year in patients with chronic hepatitis $B$.

Methods: the clinical records of 66 patients, 31 treated with lamivudine (LAM) and 35 treated with adefovir (ADF), were retrospectively reviewed. We measured viral DNA at months 1,3 and 6.

Results: the LAM group showed virological response (VR) in $51.6 \%$ of patients. Baseline VL was higher in non responders $(5.37 \pm 1.16$ vs. $7.01 \pm 1.05 ; p<0.001)$. Responders showed a higher percentage of VL decrease at month 3 from baseline $(49.2$ vs. $38.3 \% ; p=0.03)$. We designed a ROC curve and established a cutoff point for decrease of 30\% that had $80 \%$ of negative predictive value (NPV).

The ADF group showed VR in 57.1\% of patients. Baseline VL was higher in nonresponders $(4.67 \pm 1.22$ vs. $5.78 \pm 1.34 ; p=$ 0.01 ). We observed a significant decrease in VL (log) at months 3 $(2.6 \pm 1.1$ vs. $1.3 \pm 1.3 ; p=0.03)$ and $6(2.6 \pm 1.2$ vs. $1.3 \pm$ $1.2 ; p=0.006)$. The percentage of decrease of VL from baseline was also statistically significant. We created ROC curves at months 3 and 6, and established the best cutoff points. At month 6 a decrease of $1 \log$ in VL had a NPV of $80 \%$, and a decrease of $20 \%$ in VL from baseline had 100\% NPV.

Conclusion: the decrease in viral DNA at weeks 12 and 24 can predict VR at one year in patients with chronic hepatitis $B$ treated with LAM or ADF. This could optimize treatment.
\end{abstract}

Key words: Adefovir. Lamivudine. Chronic hepatitis B. Virological response.
Received: 24-03-09.

Accepted: 22-06-09.

Correspondence: José Luis Calleja. Servicio de Gastroenterología y Hepatología. Hospital Universitario Puerta de Hierro. Manuel de Falla, 1. 28222 Majadahonda, Madrid. Spain.e-mail: jlcpan@terra.es
Llop E, de la Revilla J, Pons F, Peñas B, Martínez JL, Abreu L, Calleja JL. Decrease in viral load at weeks 12 and 24 in patients with chronic hepatitis $B$ treated with lamivudine or adefovir predicts virological response at week 48. Rev Esp Enferm Dig 2009; 101: 763-767.

\section{INTRODUCTION}

Hepatitis B virus (HBV) infection affects 350-400 million people all over the world $(1,2)$. Patients can develop chronic hepatitis, hepatic cirrhosis or hepatocellular carcinoma in $25-40 \%$ of cases $(3,4)$. The progression of liver disease depends on active viral replication, and the risk of hepatocellular carcinoma and cirrhosis development is directly proportional to persistently high viral DNA levels $(5,6)$.

The main goal of treatment in chronic hepatitis B is the prevention of cirrhosis and hepatocellular carcinoma, a reduction of liver transplant needs, an increase in survival, and improved quality of life. HBsAg loss and seroconversion to anti HBs antibodies only occur in 5\% of patients (7). This is the reason why current treatments pursue VL suppression in order to prevent disease progression $(8,10,11)$. In patients with positive $\mathrm{HBeAg}$, seroconversion to anti-HBe antibodies is also pursued (911). In the last ten years very effective treatments have been developed to inhibit viral replication. These treatments improve patients both clinically and histologically $(5,10,11)$.

Lamivudine is a nucleoside analogue that has shown efficacy in patients with chronic hepatitis B infection, specially in those with negative antigen e. Patients on lamivudine show in more than $90 \%$ of cases a quick and significant reduction of VL $(12,13)$. However, they have a high proportion of resistance. Recent reports have shown that resistant HBV variants are found in up to 
$15 \%$ of patients with positive $\mathrm{HBeAg}$, and up to $10 \%$ with negative $\mathrm{HBeAg}$ at one year after lamivudine treatment onset (14-16).

Adefovir is a nucleotide analogue and offers a biochemical and histological response similar to lamivudine $(17,18)$, however, its ability t suppress VL is lower and slower than lamivudine's (19). Adefovir has been shown to be effective in naïve patients and in lamivudine-resistant patients. When adefovir is compared to lamivudine less resistance has been found (19).

Despite the high antiviral effectiveness of adefovir and lamivudine these drugs cannot eliminate $\mathrm{HBV}$; due to this, their benefit depends on their ability to maintain VL suppression. Their inability to eradicate HBV calls for long treatment periods that otherwise increase the risk of selecting viral resistant variants. This can induce treatment failure and a worsening of liver lesions (20). Thus, appropriate follow-up is essential to early detect the appearance of resistance in order to decrease their negative impact.

Previous studies in patients with chronic hepatitis B on lamivudine have suggested that early VL measurement can identify different response patterns (21-23). These studies have correlated early nonresponse with a later development of resistance. However, not many studies have focused on viral kinetics in patients treated with lamivudine or adefovir, and the role of early VL suppression is not well established. Logically, patients without an early response will not respond later, so knowing the characteristics of this group of nonreponders would be useful in order to adopt different therapeutic strategies with them.

The aim of our study was to know whether there was an initial decrease of VL able to predict response to antiviral treatment with lamivudine or adefovir at one year in patients with chronic hepatitis B.

\section{PATIENTS AND METHODS}

We analyzed the clinical records of 66 patients with chronic hepatitis B who had started treatment with adefovir or lamivudine between 2001 and 2006 in our Unit. We did not include patients with liver cirrhosis or hepatocellular carcinoma on antiviral therapy. Of 66 patients, 31 were treated with lamivudine and 35 were treated with adefovir. Epidemiological data, HBV DNA, and alanine aminotransferase (ALT) levels at months 1, 3, 6 and 12 from treatment onset were collected. We defined VR at one year from treatment onset as the finding of undetectable DNA ( $<200$ copies by Cobas-Core ${ }^{\circledR}$ Roche) and $\mathrm{BR}$ at one year as the normalization of ALT values (ULN $40 \mathrm{U} / \mathrm{L}$ ). We measured the decrease in viremia in logarithms and in percentage of decrease from baseline.

Two groups of treatment were analyzed independently. Continuous data were represented with mean \pm standard deviation, while categorical data were represented in frequencies (\%). Continuous variable comparisons were done with Student's t-test. Categorical data were compared with the $\chi^{2}$ test. ROC curves were made in order to define the best cutoff points for decrease in viral load able to predict VR at one year from treatment onset. Statistical signification was established at $p=0.05$. The statistical analysis was done with SPSS 13.0 ( ${ }^{\circ}$ SPS inc., Chicago, IL, USA) for Windows ${ }^{\circledR}$ XP (Microsoft Corp.).

\section{RESULTS}

\section{Lamivudine}

Of all 66 patients, 31 received lamivudine. Table I shows the baseline characteristics of patients - mean age was 38 years (SD 12), with male and negative $\mathrm{HBeAg}$ predominance. Infection transmission was unknown in the majority of cases, and 10 patients had received previous treatments with alfa-interferon or pegilated interferon.

We observed VR in 16/31 (51.6\%) patients, and BR in $22 / 31(70.96 \%)$ patients. Responders had a significantly lower VL $(\log )$ as compared to nonresponders $(7.01 \pm$ 1.05 vs. $5.37 \pm 1.16 ; \mathrm{p}<0.001)$. The decrease in logarithms and in percentage of decrease from baseline for responders and nonresponders are shown in table II. The decrease in logarithms for responders and nonresponders was similar. We only observed significant differences in the percentage of VL decrease from baseline at month 3 . This decrease was higher in responders (49.2 vs. 38.3\%; $\mathrm{p}=0.03)$. These data allowed to create a ROC curve (AUC $=0.675)$ (Fig. 1) and to establish a cutoff point for VL decrease from baseline equal to or less than $30 \%$, which had a sensitivity of $92 \%$ and a negative predictive value of $80 \%$.

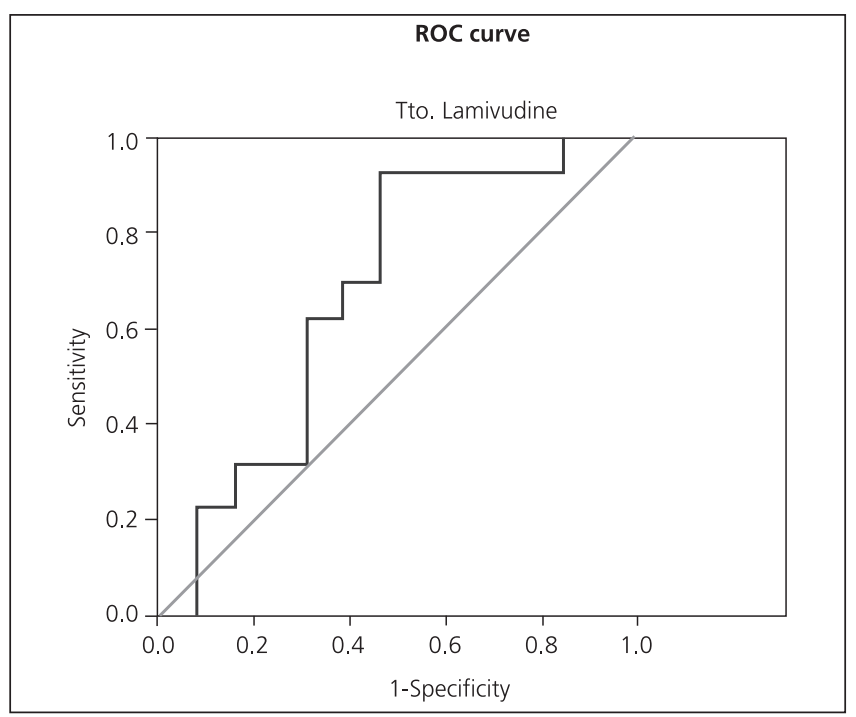

Fig. 1. ROC curve at month 3 from treatment onset with lamivudine $(A \cup C=0.675)$. 
We included 10 patients with positive $\mathrm{HBeAg}$ and 21 patients with negative $\mathrm{HBeAg}$ in the lamivudine group. Patients with positive HBeAg had a higher baseline VL than patients with negative $\mathrm{HBeAg}(6.7$ vs. $5.9 \mathrm{log} ; \mathrm{p}=$ 0.7). Three (30\%) patients with positive HBeAg showed VR at one year from treatment onset. Thirteen $(61.9 \%)$ of the patients with negative $\mathrm{HBeAg}$ showed VR at one year from treatment onset. Due to the small number of patients with positive $\mathrm{HBeAg}$ it was impossible to compare decreases in VL and to create ROC curves to find different cutoff points that could predict response at one year from treatment onset. Negative $\mathrm{HBeAg}$ patients had significant differences between nonresponders and responders in the percentage of $\mathrm{VL}$ decrease from baseline at month 3 (44.0 vs. 52.5\%; $\mathrm{p}=0.005)$. We created a ROC curve $(\mathrm{AUC}=0.6)$ at month 3 and found a cutoff point equal to or less than $30 \%$ that had $100 \%$ sensitivity and $100 \%$ negative predictive value.

\section{Adefovir}

Of all 66 patients with chronic hepatitis B, 35 received adefovir. The baseline characteristics of patients are shown in table I. Mean age was 42 (SD 14) years, with male sex and negative $\mathrm{HBe} A g$ predominance. The transmission of infection was unknown in most cases. Of 35 patients, 24 had received lamivudine before, and 2 had received alfa-interferon or pegilated interferon.

In this group, 20 out of $34(57.1 \%)$ had VR and 25 out of $34(73.5 \%)$ had BR. Responders had a lower baseline VL $(\log )$ compared to nonresponders $(4.67 \pm 1.22 \mathrm{vs}$. $5.78 \pm 1.34 ; \mathrm{p}=0.01)$. Besides, there was a significant decrease in logarithms in the group of responders at months $3(2.6 \pm 1.1$ vs. $1.3 \pm 1.3 ; \mathrm{p}=0.03)$, and $6(2.6 \pm$ 1.2 vs. $1.3 \pm 1.2 ; \mathrm{p}=0.006$ ) from treatment onset with adefovir (Table II). The decrease in VL from baseline (\%) was also significantly higher in responders at months 1,3 and 6 from treatment onset. With these data we created ROC curves at months 3 and 6 for VL decrease in logarithms and in percentage of decrease from baseline (Figs. 2 and 3), and established the best cutoff points to predict
Table I. Baseline characteristics of patients treated with lamivudine and adefovir

\begin{tabular}{lcc}
\hline & $\begin{array}{c}\text { Lamivudine } \\
(n=31)\end{array}$ & $\begin{array}{c}\text { Adefovir } \\
(n=35)\end{array}$ \\
\hline $\begin{array}{l}\text { Age at treatment onset } \\
\text { (years) }\end{array}$ & $38($ SD 12) & 42 (SD 14) \\
\hline $\begin{array}{l}\text { Sex } \\
\text { (male:female) }\end{array}$ & $24: 7$ & $31: 4$ \\
\hline $\begin{array}{l}\text { Transmission } \\
\text { Transfusion }\end{array}$ & 6 & \\
$\begin{array}{l}\text { Sexual } \\
\text { Perinatal }\end{array}$ & 1 & 4 \\
Surgery & 3 & 2 \\
Surgery & 1 & 1 \\
\hline HBeAg & 20 & 24 \\
$(+:-)$ & $10: 21$ & $11: 24$ \\
\hline
\end{tabular}

VR at one year from treatment onset. At month 6 a decrease in viral load of $1 \log$ had $93 \%$ sensitivity and $80 \%$ negative predictive value, and a percentage of VL decrease from baseline equal to or less than $20 \%$ had $100 \%$ sensitivity and $100 \%$ negative predictive value.

There were 11 patients with positive $\mathrm{HBeAg}$ and 24 patients with negative $\mathrm{HBeAg}$. Baseline VL was higher in patients with positive $\mathrm{HBeAg}(6.2$ vs. $4.7 \mathrm{log}$; $\mathrm{p}=0.2)$. VR at one year from treatment onset was higher in negative HBeAg patients (75.0 vs. $18.2 \%, \mathrm{p}=0.002)$. Negative and positive $\mathrm{HBeAg}$ responders showed higher VL decreases during follow-up, both in logarithms and in percentage of VL decrease from baseline. The small number of patients with positive $\mathrm{HBeAg}$ did not allow comparisons between responders and nonresponders. In the group of negative $\mathrm{HBeAg}$ subjects the percentage of VL decrease from baseline was significantly higher in responders (48.4 vs. 31.14; $\mathrm{p}=0.02)$. This allowed to create a ROC curve (AUC $=0.8)$ and to establish a cutoff point for VL decrease equal to or less than $20 \%$ from baseline that had $100 \%$ sensitivity and $100 \%$ negative predictive value.

Table II. Differences in pattern of viral load decrease in responders $v s$. nonresponders to lamivudine and adefovir

\begin{tabular}{|c|c|c|c|c|c|c|c|}
\hline & & \multicolumn{3}{|c|}{ Lamivudine } & \multicolumn{3}{|c|}{ Adefovir } \\
\hline & & Responders & Non responders & $p$ & Responders & Non responders & $p$ \\
\hline \multirow{3}{*}{$\begin{array}{l}\text { Mean VL decrease in } \\
\text { logarithms (log) }\end{array}$} & Month 1 & $1.2( \pm 1.8)$ & $2.7( \pm 1.3)$ & 0.2 & $1.6( \pm 1.1)$ & $0.8( \pm 1.4)$ & 0.2 \\
\hline & Month 3 & $2.7( \pm 0.99)$ & $2.7( \pm 1.5)$ & 0.9 & $2.4( \pm 1.1)$ & $1.3( \pm 1.3)$ & 0.03 \\
\hline & Month 6 & $2.8( \pm 1.2)$ & $3.5( \pm 1.3)$ & 0.2 & $2.6( \pm 1.2)$ & $1.3( \pm 1.2)$ & 0.006 \\
\hline \multirow{3}{*}{$\begin{array}{l}\text { Mean VL decrease from } \\
\text { baseline (\%) }\end{array}$} & Month 1 & $19.5( \pm 26.3)$ & $33.5( \pm 13.6)$ & 0.3 & $32.1( \pm 17.6)$ & $11( \pm 21.9)$ & 0.05 \\
\hline & Month 3 & $49.2( \pm 13.2)$ & $38.3( \pm 20.4)$ & 0.03 & $46.6( \pm 13.9)$ & $19.9( \pm 20.0)$ & 0.001 \\
\hline & Month 6 & $52.1( \pm 14.5)$ & $50.8( \pm 15.4)$ & 0.8 & $49.3( \pm 12.7)$ & $21.1( \pm 19.8)$ & $<0.001$ \\
\hline
\end{tabular}




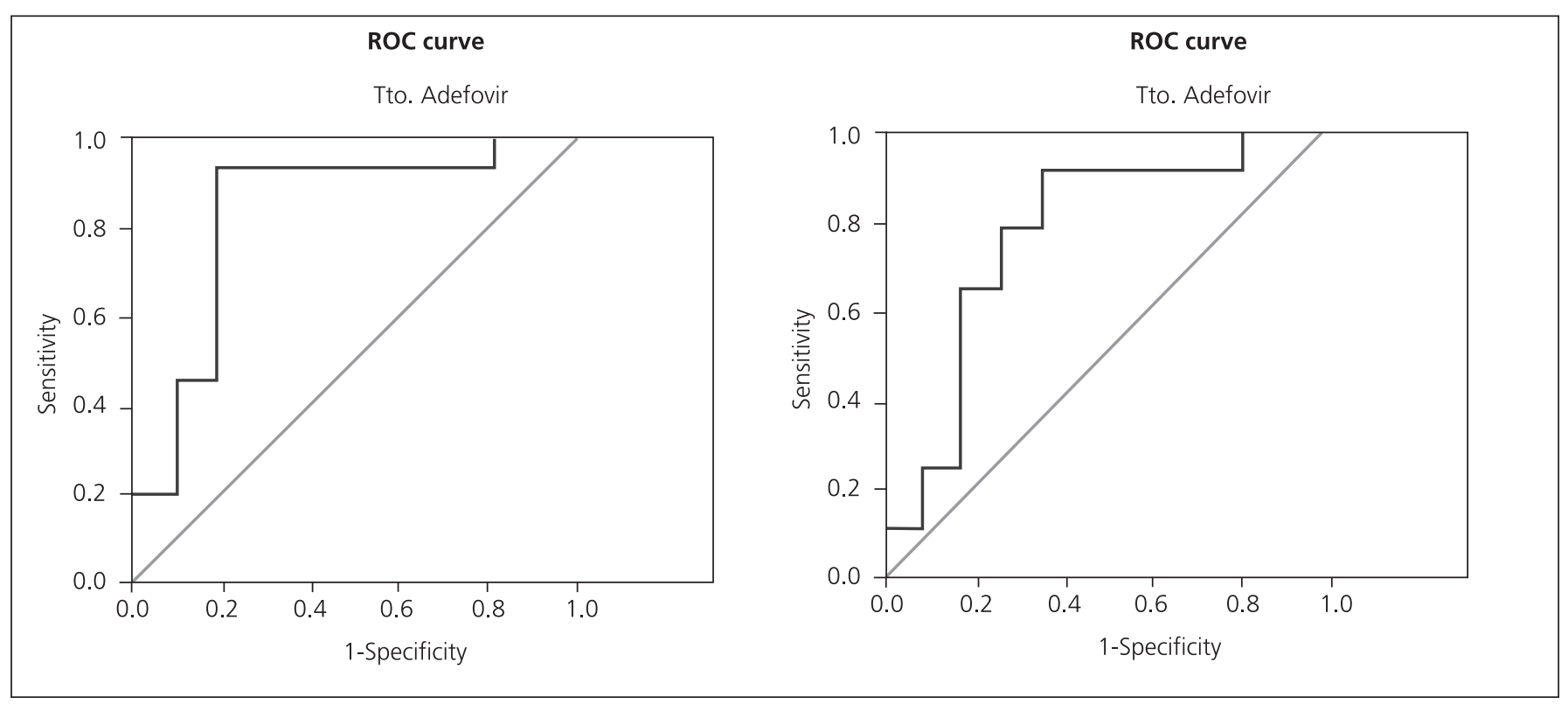

Fig. 2. ROC curves at month 3 from treatment onset with adefovir. A. VL decrease in percentage from baseline; $A U C=0.83 .2$. Decrease in logarithms of viral load; $A \cup C=0.77$.

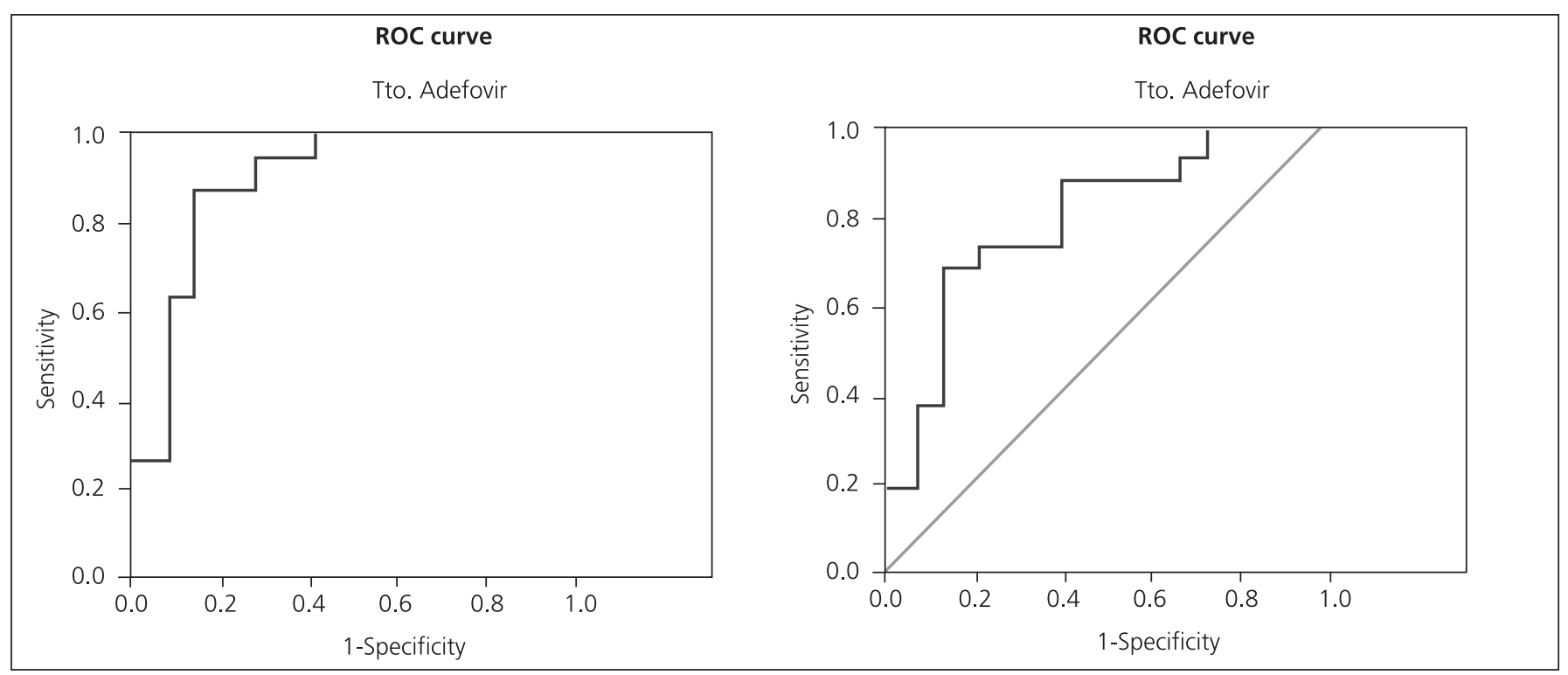

Fig. 3. ROC curves at month 6 from treatment onset with adefovir. A. VL decrease in percentage from baseline; $A U C=0.9$. B. VL decrease in logarithms; $A \cup C=0.79$.

\section{DISCUSSION}

Our results show that patients treated with lamivudine, whether with or without VR, had a similar pattern of VL decrease in logarithms during follow-up. The absence of differences between groups is probably due to the high antiviral potency of lamivudine that causes an important decrease in viral load in nonresponders, but not enough as they have a higher baseline viral load. The persistence of viral replication in nonresponders increases the risk of resistance in these patients and difficults VR at one year from treatment onset. These findings agree with those of Buti et al. (23) in which baseline DNA levels in 15 patients with YMDD variants at one year of antiviral treatment with lamivudine were significantly higher than those of 19 patients without these variants $(8.42 \pm 1.16$ $v s .7 .58 \pm 1.01 ; \mathrm{p}=0.033)$. Besides, that study did not observe differences in mean VL decrease (logarithms) at month three since treatment onset $(3.86 \pm 1.32 v s .3 .8 \pm$ $1.32 ; \mathrm{p}=\mathrm{NS})$. 
In our study we observed a higher decrease in VL from baseline in responders at months 3 and 6 since treatment onset. The decrease at month three was statistically significant. Besides, we established a cutoff point equal to or less than $30 \%$ that allowed us to recognize patients that had not responded early. This shows that a patient that cannot decrease his or her VL more that $30 \%$ by month three from baseline will not have VR at one year from treatment onset $(\mathrm{NPV}=80 \%)$. In patients treated with lamivudine this value can be helpful to consider other alternative or add-on treatments.

Differences observed between responders and nonresponders were more patent in patients treated with adefovir. There was a higher reduction of viral load in responders (in logarithms and in percentage of decrease from baseline). These differences were more important at months 3 and 6 from treatment onset. The best cutoff points that allowed us to define the patient with early response to adefovir were at month 6 of treatment. This can be due to differences in antiviral effectiveness between lamivudine and adefovir. As lamivudine is more powerful, it may identify nonresponders earlier. Patients with a decrease of one or less than one logarithm at month 6 of treatment were included in the group of early nonresponders with a negative predictive value of $80 \%$. The determination of VL from baseline at month 6 was even more precise as a decrease lower than or equal to $20 \%$ was able to identify nonresponders to adefovir with a negative predictive value of $100 \%$.

When we analyzed separately patients with positive and negative $\mathrm{HBeAg}$ treated with both drugs it was impossible to draw conclusions in the group of patients with positive HBeAg due to the small number of patients. The results were similar to those of the global group in patients with negative $\mathrm{HBeAg}$.

Although our study had a small series of patients, our results suggest that early VL determination can predict virological response at one year in patients with chronic hepatitis B, especially in those on adefovir, and identify nonresponders early. Prospective studies with larger series of patients would be necessary to confirm these results.

\section{REFERENCES}

1. Lavanchy D. Hepatitis B virus epidemiology, disease burden, treatment and current and emerging prevention and control measures. $\mathrm{J}$ Viral Hepat 2004; 11(2): 97-107.

2. Dienstag JL. Hepatitis B virus infection. 2008; 359(14): 1486-500.

3. Chu CM, Liau YF. Natural history of chronic B virus infection: an immunopathological study. J Gastroenterol Hepatol 1997; 12(9-10): S218-22.

4. Ganem D, Prince AM. Hepatitis B virus infection-natural history and clinical consequences. N Engl J Med 2004; 350(11): 1118-29.
5. Iloeje UH, Yang HI, Su J, Jen CL, You SL, Chen CJ. Risk evaluation of viral load elevation and associated liver disease/cancer-in HBV (the REVEAL-HBV) Study Group. Predicting cirrhosis risk based on the level of circulating hepatitis B viral load. Gastroenterology 2006; 130(3): 678-86.

6. Chen CJ, Yang HI, Su J, Jen CL, You SL, Lu SN, et al.; REVEALHBV Study Group. Risk of hepatocellular carcinoma across a biological gradient of serum hepatitis B virus DNA level. JAMA 2006; 295(1): 65-73.

7. Hoofnagle JH, Doo E, Liang TJ, Fleischer R, Lok AS. Management of hepatitis B: summary of a clinical research workshop. Hepatology 2007; 45(4): 1056-75.

8. Lai CL, Gane E, Liaw YF, Hsu CW, Thongsawat S, Wang Y, et al.; Globe Study Group. Telbivudine versus lamivudine in patients with chronic hepatitis B. N Engl J Med 2007; 357(25): 2576-88.

9. Sánchez-Tapias JM. Pharmacological agents for the treatment of chronic hepatitis B. Gastroenterol Hepatol 2008; 31(3): 120-8.

10. European Association for the Study of the Liver. EASL Clinical Practice Guidelines: Management of chronic hepatitis B. Journal of Hepatology 2009; 50: 227-42.

11. Lok AS. Navigating the maze of hepatitis B treatments. Gastroenterology 2007; 132(4): 1586-94.

12. Nevens F, Main J, Honkoop P, Tyrrell DL, Barber J, Sullivan MT, et al. Lamivudine therapy for chronic hepatitis B: a six month randomized dose-range study. Gastroenterology 1997; 113(4): 1258-63.

13. Tassopoulos NC, Volpes R, Pastore G, Heathcote J, Buti M, Goldin $\mathrm{RD}$, et al. Efficacy of lamivudine in patients with hepatitis B e antigen-e negative/hepatitis B virus DNA positive (pre-core mutant) chronic hepatitis B. Hepatology 1999; 29(3): 889-96.

14. Buti M, Cotrina M, Jardi R, de Castro EC, Rodriguez-Frias F, Sánchez-Avila F, et al. Two years of lamivudine therapy in anti-HBe positive patients with chronic hepatitis B. J Viral Hepat 2001; 8(4): 270-5.

15. Liaw YF, Sung JJ, Chow WC, Farrell G, Lee CZ, Yuen H, et al. Cirrhosis Asian Lamivudine Multicentre Study Group. Lamivudine for patients with chronic hepatitis B and advanced liver disease. N Engl J Med 2004; 351(15): 1521-31.

16. Hadziyannis SJ, Papatheodoridis GV, Dimou E, Laras A, Papaioannou $C$. Efficacy of long-term lamivudine monotherapy in patients with hepatitis B e antigen-negative chronic hepatitis B. Hepatology 2000; 32(4 Pt 1): 847-51.

17. Peters MG, Hann HW H, Martin P, Heathcote EJ, Buggisch P, Rubin $\mathrm{R}$, et al. Adefovir dipivoxil alone or in combination with lamivudine in patients with lamivudine-resistant chronic hepatitis B. Gastroenterology 2004; 126(1): 91-101.

18. Perrillo R, Hann HW, Mutimer D, Willems B, Leung N, Lee WM, et al. Adefovir dipivoxil added to ongoing lamivudine in chronic hepatitis B with YMDD mutant hepatitis B virus. Gastroenterology 2004; 126(1): 81-90.

19. Fung SK, Chae HB, Fontana RJ, Conjeevaram H, Marrero J, Oberhelman $\mathrm{K}$, et al. Virologic response and resistance to adefovir in patients with lamivudine-resistance chronic hepatitis B. J Hepatol 2006; 44(2): 283-90

20. Revilla J, Pons F, Calleja JL. Resistencias al virus B y terapias combinadas. J Clin Gastroenterol Hepatol 2007; 7: 7-24.

21. Gauthier J, Bourne EJ, Lutz MW, Crowther LM, Dienstag JL, Brown NA, et al. Quantification of hepatitis B viremia and emergence of YMDD variants in patients with chronic hepatitis B treated with lamivudine. J Infect Dis 1999; 180(6): 1757-62.

22. Puchhammer-Stöckl E, Mandl CW, Kletzmayr J, Holzmann H, Hofmann A, Aberle SW, et al. Monitoring the virus load can predict the emergence of drug-resistant hepatitis B virus strains in renal transplantation patients during lamivudine therapy. J Infect Dis 2000; 181(6): 2063-6

23. Buti M, Sánchez F, Cotrina M, Jardi R, Rodríguez F, Esteban R, et al. Quantitative Hepatitis B Virus DNA testing for the early prediction of the maintenance of response during lamivudine therapy in patients with chronic hepatitis B. J Infect Dis 2001; 183(8): 1277-80. 